\title{
circRNA-CER mediates malignant progression of breast cancer through targeting the miR-136/MMP13 axis
}

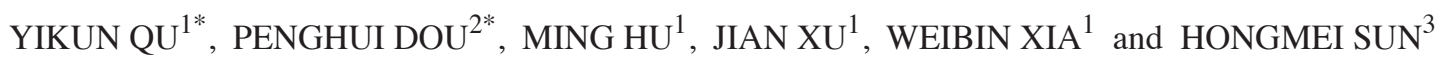 \\ Departments of ${ }^{1}$ General Surgery, and ${ }^{2}$ Radiation and Chemotherapy, First Affiliated Hospital of Jiamusi University; \\ ${ }^{3}$ Department of Oncology, Oncology Hospital of Jiamusi City, Jiamusi, Heilongjiang 154002, P.R. China
}

Received August 29, 2018; Accepted February 13, 2019

DOI: $10.3892 / \mathrm{mmr} .2019 .9965$

\begin{abstract}
Chondrocyte extracellular matrix-related circular RNAs (circRNA-CER) have been demonstrated to be involved in various diseases. However, its role in the development of human breast cancer is not clearly understood. The aims of the present study were to assess circRNA-CER expression in paired cancer tissue and adjacent non-tumor tissue from 24 patients with breast cancer, and to explore the roles and mechanisms by which circRNA-CER mediates the malignant progression of breast cancer cells. The results revealed that circRNA-CER and matrix metalloproteinase 13 (MMP13) were upregulated, whereas miR-136 was downregulated in breast cancer tissues compared with adjacent non-tumor tissues. In vitro silencing of circRNA-CER using small interfering RNA (siRNA) had inhibitory effects on MCF-7 breast cancer cell proliferation and migration, and similar results were obtained following overexpression of microRNA (miR)-136 in MCF-7 cells by transfection with miR-136 mimics. The subsequent mechanistic study revealed that the expression levels of MMP13 were significantly lower in MCF-7 cells following transfection with miR-136 mimics, and silencing of circRNA-CER enhanced miR-136 and decreased MMP13 expression levels. Furthermore, silencing of miR-136 by transfection with miR-136 inhibitors resulted in an increase in MCF-7 cell proliferation and migration. miR-136 inhibitor-derived biological effects were reversed by co-transfection of cells with miR-136 inhibitors and circRNA-CER siRNA. Taken together, the present results suggested that circRNA-CER may serve an important role in the progression of breast cancer by regulating the activity of the miR-136/MMP13 axis, and may be a potential biomarker for the prediction and treatment of breast cancer.
\end{abstract}

Correspondence to: Dr Hongmei Sun, Department of Oncology, Oncology Hospital of Jiamusi City, 37 Guanghua Road, Jiamusi, Heilongjiang 154002, P.R. China

E-mail:shm1357@163.com

*Contributed equally

Key words: circRNA-CER, breast cancer, MMP13, miR-136

\section{Introduction}

Breast cancer is the most frequently diagnosed cancer type and the fifth most common cause of mortality among women worldwide (1). It was estimated that there were 268,600 newly diagnosed cases and 69,500 patients that succumbed to this disease in China in 2015, which accounts for $15.1 \%$ of all cancer incidences and $6.9 \%$ of cancer-related mortalities in women (2). Although the mortality rates due to breast cancer have declined, the incidence rates of this disease have increased in China over the past decades (3). Breast cancer is a heterogeneous disease that can be classified into several forms based on histological, clinical and genetic features. Numerous attempts of categorizing this heterogeneous disease have led to a molecular classification into five subgroups by gene-expression profiling $(4,5)$.

Circular RNAs (circRNAs) are large non-coding RNAs that are present ubiquitously in the cytoplasm of eukaryotic cells and function as competing endogenous RNAs (6). Numerous circRNAs serve important 'sponge' roles through their effect on microRNA (miR/miRNA) activity. For example, circRNA ciRS-7 is a newly identified human circRNA that is involved in resistance to miRNA-mediated target destabilization, by strongly binding and suppressing the activity of miR-7 (7). A previous report also revealed the crucial role of circRNAs in regulating gene transcription (8). Accumulating evidences have demonstrated that circRNAs have remarkable regulatory roles in the generation and development of various diseases, including atherosclerosis, nervous system disorders and cancers, including leukemia and solid tumors (9-11). A recent study demonstrated that chondrocyte extracellular matrix-related ciRNA (circRNA-CER) expression increases with increased levels of interleukin-1 and tumor necrosis factor in chondrocytes, and silencing of circRNA-CER using small interfering RNA (siRNA) suppresses matrix metalloproteinase 13 (MMP13) expression and increases extracellular matrix formation (12). Yao et al suggested that the expression of circRNA-CER is significantly associated with lymph node metastasis, overall survival and tumor stage in non-small cell lung cancer (13). However, the function of circRNA-CER in breast cancer remains largely unknown and requires further investigation.

The present study aimed to evaluate the expression profiles of circRNA-CER in breast cancer and investigate their potential role in the disease. The data demonstrated that the expression levels of circRNA-CER in breast cancer tissue were 
significantly higher compared with in adjacent non-tumor tissue, and that circRNA-CER may function as a competing endogenous RNA to regulate the expression of MMP13 by competing with miR-136 in breast cancer cells. To the best of our knowledge the present study demonstrated for the first time a positive circRNA-CER/MMP13 association, and crosstalk among miR-136, circRNA-CER and MMP13, which provides novel insight into the treatment of breast cancer.

\section{Materials and methods}

Patients and tissue samples. A total of 24 surgically resected tissue specimens from female patients with breast cancer were collected from the First Affiliated Hospital of Jiamusi University (Jiamusi, China) from April 2016 to March 2018. Patients who had received local or systemic therapy prior to surgery were excluded from the study, and the ages of the patients ranged from 38-73 years old. Pathological examination of the tissue specimens was conducted independently by three pathologists, without prior knowledge of the patients' medical records. The present study was approved by the Ethics Committee of Jiamusi University (approval no. JMSU-215) and all patients provided written informed consent prior to enrolment.

Immunohistochemistry. The tissue samples were fixed in $10 \%$ buffered formalin at room temperature for $24 \mathrm{~h}$, embedded in paraffin, and cut into $5 \mu \mathrm{m}$-thick sections. Following deparaffinization in xylene at $37^{\circ} \mathrm{C}$ for $30 \mathrm{~min}$, the sections were dehydrated in a graded series of ethanol, subjected to antigen retrieval with $0.01 \mathrm{M}$ citrate buffer (cat. no. AR0024; Wuhan Boster Biological Technology, Ltd., Wuhan, China) at $100^{\circ} \mathrm{C}$ for $18 \mathrm{~min}$ in a high-pressure cooker and washed in PBS (cat. no. AR0030; Wuhan Boster Biological Technology, Ltd.) at room temperature for $5 \mathrm{~min}$. Endogenous peroxidase activity was subsequently quenched by incubating the sections with $3 \%$ hydrogen peroxide in PBS for $15 \mathrm{~min}$ at room temperature, followed by blocking with $5 \%$ bovine serum albumin (BSA, cat. no. AR0004; Wuhan Boster Biological Technology, Ltd.) at $37^{\circ} \mathrm{C}$ for $60 \mathrm{~min}$. Then, the slides were incubated with a rabbit polyclonal anti-MMP13 primary antibody (1:150; cat. no. ab39012; Abcam, Cambridge, MA, USA) overnight at $4^{\circ} \mathrm{C}$. As a negative control, the primary antibody was replaced with the same amount of normal rabbit serum (cat. no. AR0010; Wuhan Boster Biological Technology, Ltd.). Following several washes in PBS (3x3 min) to remove the excess of antibody, a biotin-conjugated goat anti-rabbit secondary antibody (cat. no. SA1022; Wuhan Boster Biological Technology, Ltd.) was applied at $37^{\circ} \mathrm{C}$ for $20 \mathrm{~min}$, followed by washing of slides in PBS (3x3 min). Next, the slides were incubated in avidin-biotin peroxidase complex (cat. no. SA1022; Wuhan Boster Biological Technology, Ltd.) for $20 \mathrm{~min}$ at $37^{\circ} \mathrm{C}$. Then, 3,3'-diaminobenzidine (Beijing Biosynthesis Biotechnology Co., Ltd, Beijing, China) was used for chromogenic detection and slides were counterstained with hematoxylin at room temperature for $30 \mathrm{~min}$ for cell nuclear detection.

MMP13 protein expression was quantified based on the staining intensity and proportion of stained cells, according to Li et al (14) with slight modifications. Briefly, MMP13 staining intensity was scored from 0 to 3 as follows: 0 , absent immunopositivity; 1, low immunopositivity; 2, moderate immunopositivity;
3 , intense immunopositivity. The extent of total staining was scored from 0 to 4 as follows: 0 , negative; $1,1-25 \%$ of cells; $2,26-50 \%$ of cells; $3,51-75 \%$ of cells; and $4,76-100 \%$ of cells. On average, three random fields were observed for each tissue at X400 magnification under an Olympus BX-60 fluorescence microscope (Olympus Corporation, Tokyo, Japan). The final staining score was the sum of the intensity and extent scores.

Cell lines, cell culture and transfection. The MCF-7 and ZR-75-30 breast cancer cell lines were purchased from the Shanghai Institute of Biochemistry and Cell Biology (Shanghai, China). Cells were cultured in RPMI-1640 medium (Gibco; Thermo Fisher Scientific, Inc., Waltham, MA, USA) supplemented with $10 \%$ fetal bovine serum (FBS; Gibco; Thermo Fisher Scientific, Inc.), 100 U/ml penicillin and $100 \mathrm{mg} / \mathrm{ml}$ streptomycin(Invitrogen; Thermo Fisher Scientific, Inc.) at $37^{\circ} \mathrm{C}$ with $5 \% \mathrm{CO}_{2}$ in a humidified atmosphere. miR-136 mimics, miR-136 inhibitors and the corresponding negative controls were designed and constructed by Shanghai Gene Pharma Co., Ltd. (Shanghai, China). siRNA targeting circRNA-CER (si-circRNA-CER) and its negative controls were purchased from Guangzhou RiboBio Co., Ltd. (Guangzhou, China). The sequences for miR-136 mimics, miR-136 inhibitors and si-circRNA-CER were: 5'-ACUCCAUUUGUUUUGAUG AUGGA-3', 5'-CAUCAUCGUCUCAAAUGAGUCU-3' and 5'-CCCACGCUCCUACAAUGUU-3'. Transfection of MCF-7 cells was performed using Lipofectamine ${ }^{\circledR} 2000$ (Invitrogen; Thermo Fisher Scientific, Inc.), according to the manufacturer's instructions. Briefly, Lipofectamine ${ }^{\circledR} 2000$ was incubated with miRNAs at a concentration of $100 \mathrm{nmol} / \mathrm{l}$ or siRNAs at a concentration of $200 \mathrm{nmol} / 1$ for $20 \mathrm{~min}$, and the complex was then added to each well. Following transfection for $24 \mathrm{~h}$, the subsequent experiments were performed.

Reverse transcription-quantitative polymerase chain reaction (RT-qPCR). Specific primers for circRNA-CER, $\beta$-actin, miRNA-136 and U6 were purchased from GeneCopoeia, Inc. (Rockville, MD, USA). The primers used in this investigation were: circRNA-CER forward: 5'-CTGGTGCAG TGGAAGCAGAG-3', reverse: 5'-CGACCCTCCATTGCT CTTCT-3'; $\beta$-actin forward: 5'-CTCCATCCTGGCCTC GCTGT-3', reverse: 5'-GCTGTCACCTTCACCGTTCC-3'; miRNA-136 forward: 5'-ACUCCAUUUGUUUUGAUGAUG GA-3', reverse: 5'-UCCAUCAUCAAAACAAAUGGAGU-3', U6 forward: 5'-GCTTCGGCAGCACATATACTAAAAT-3', reverse: 5'-CGCTTCACGAATTTGCGTGTCAT-3'. For detection of circRNA-CER, total RNA from cells and tissues was isolated using TRIzol ${ }^{\circledR}$ reagent (Invitrogen; Thermo Fisher Scientific, Inc.), and reverse transcribed using the iScript ${ }^{\mathrm{TM}}$ cDNA Synthesis kit (Bio-Rad Laboratories, Inc., Hercules, CA, USA), according to the manufacturer's protocols. circRNA-CER PCR amplifications were performed using a Super Real Pre Mix Color (SYBR Green) Real Time PCR kit(cat. no. FP215; Tiangen Biotech Co., Ltd., Beijing, China) with the following conditions: Denaturation at $95^{\circ} \mathrm{C}$ for $10 \mathrm{~min}$, followed by 40 cycles of $95^{\circ} \mathrm{C}$ for $10 \mathrm{sec}, 60^{\circ} \mathrm{C}$ for $20 \mathrm{sec}$ and $72^{\circ} \mathrm{C}$ for $10 \mathrm{sec}$. Relative expression of miR-136 was determined with the All-in-One ${ }^{\mathrm{TM}}$ miRNA qRT-PCR Detection kit based on SYBR Green dye method (cat. no. AOMD-Q020; GeneCopoeia, Inc.), according to the manufacturer's protocol. miR-136 PCR amplifications were performed using the following conditions: 
Denaturation at $95^{\circ} \mathrm{C}$ for $10 \mathrm{~min}$, followed by 40 cycles of $95^{\circ} \mathrm{C}$ for $15 \mathrm{sec}, 60^{\circ} \mathrm{C}$ for $20 \mathrm{sec}$ and $72^{\circ} \mathrm{C}$ for $12 \mathrm{sec}$. The expression levels of circRNA-CER and miR-136 were evaluated using the comparative quantification method (15), and normalized to $\beta$-actin and U6 expression levels, respectively.

Cell proliferation assay. Cell proliferation was determined using the Cell Counting Kit-8 (CCK-8; cat. no. AR1160; Wuhan Boster Biological Technology, Ltd.), according to the manufacturer's protocols. Briefly, cells were plated in a 96-well plate $\left(1 \times 10^{2}\right.$ cells/well) and cultured in $100 \mu \mathrm{l}$ RPMI-1640 medium supplemented with $10 \%$ FBS, $100 \mathrm{U} / \mathrm{ml}$ penicillin and $100 \mu \mathrm{g} / \mathrm{ml}$ streptomycin. Following incubation at $37^{\circ} \mathrm{C}$ for $24,48,72$ or $96 \mathrm{~h}, 10 \mu \mathrm{l}$ CCK-8 reagent was added to each well and cells were further incubated for $1 \mathrm{~h}$. Cell proliferation analysis was subsequently performed by measuring absorbance at wavelength $450 \mathrm{~nm}$ using a spectrophotometer (BioTek Instruments, Inc., Winooski, VT, USA).

Cell migration assay. Migration of MCF-7 cells was evaluated using Transwell inserts (pore size, $8 \mu \mathrm{m}$; Corning, Inc., Corning, NY, USA) in a 24 -well plate. Briefly, $2 \times 10^{4}$ cells (for miR-136 mimics and si-circRNA-CER assays) or $5 \times 10^{3}$ cells (for miR-136 inhibitors assays) were resuspended in $100 \mu 1$ serum-free RPMI-1640 medium and seeded in the top chamber of each Transwell insert in triplicate. A total of $600 \mu \mathrm{l}$ RPMI-1640 medium containing $10 \%$ FBS was added to the lower chamber. After $48 \mathrm{~h}$ of incubation at $37^{\circ} \mathrm{C}$, cells in the top chamber were removed by scraping with a cotton swab, and the inserts were fixed with $4 \%$ paraformaldehyde at room temperature for $30 \mathrm{~min}$ and stained with $0.5 \%$ crystal violet at room temperature for $15 \mathrm{~min}$. Cells were visualized under a light microscope at x100 magnification (Olympus Corporation) and migrating cells in five random microscopic fields were counted.

Western blot analysis. Western blotting was performed to detect MMP13 protein expression. Total protein was extracted from cells using RIPA lysate (cat. no. AR0105; Wuhan Boster Biological Technology, Ltd.). Following quantification of protein concentration using a BCA assay kit (cat. no. AR0146A; Wuhan Boster Biological Technology, Ltd.), a total of $50 \mu \mathrm{g}$ total protein was subjected to $12 \%$ SDS-PAGE. Following transfer to polyvinylidene fluoride membranes (EMD Millipore, Billerica, MA, USA), the membranes were blocked with $5 \%$ non-fat milk at $37^{\circ} \mathrm{C}$ for $2 \mathrm{~h}$ and probed with rabbit polyclonal anti-MMP13 (1:5,000; cat. no. ab39012; Abcam) and mouse monoclonal anti-GAPDH (1:1,000; cat. no. ab8245; Abcam) primary antibodies at $37^{\circ} \mathrm{C}$ for $2 \mathrm{~h}$. The membranes were washed twice for $5 \mathrm{~min}$ in tris-buffered saline containing $0.05 \%$ Tween-20, and subsequently incubated with horseradish peroxidase-conjugated goat anti-rabbit or goat anti-mouse secondary antibodies (1:10,000; cat. nos. BA1054 and BA1050; Wuhan Boster Biological Technology, Ltd.) with gentle shaking at $37^{\circ} \mathrm{C}$ for $25 \mathrm{~min}$. The protein bands were visualized using the Beyo ECL Star kit (cat. no. P0018A; Beyotime Institute of Biotechnology, Jiangsu, China) and quantified by the Image Quant TL software (GE Healthcare Life Sciences, Little Chalfont, UK).

Statistical analysis. All experiments were repeated three times. The data are presented as the mean \pm standard deviation.
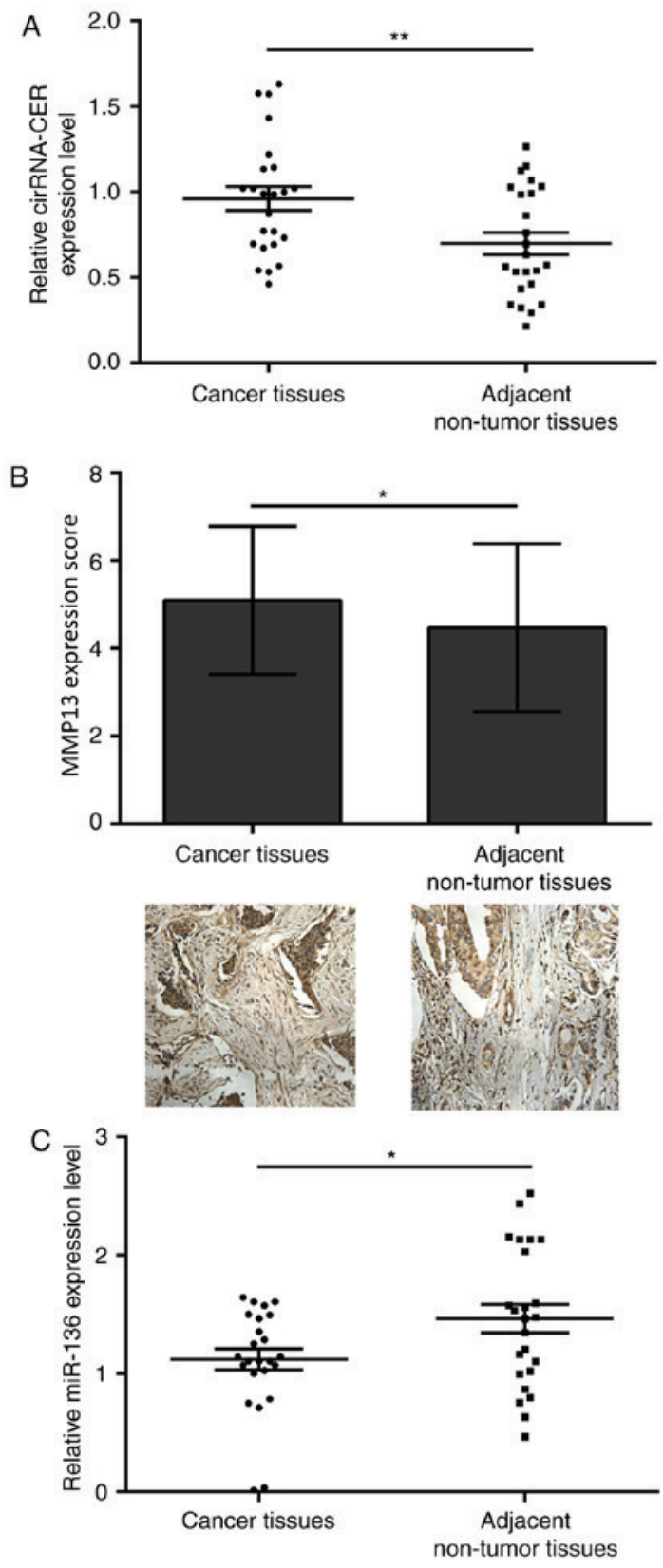

Figure 1. Relative expression levels of circRNA-CER, MMP13 and miR-136 in the tissues of patients with breast cancer. Comparison of (A) circRNA-CER, (B) MMP13 (magnification, $\mathrm{x} 200$ ) and (C) miR-136 expression levels in breast cancer tissues and adjacent non-tumor tissues $(n=24)$, using reverse transcription-quantitative polymerase chain reaction and immunohistochemistry. ${ }^{*} \mathrm{P}<0.05,{ }^{* *} \mathrm{P}<0.01$. circRNA-CER, chondrocyte extracellular matrix-related circular RNA; MMP13, matrix metalloproteinase 13; miR, microRNA.

Comparison of two means was performed using Student's t-test, whereas comparison of multiple means was conducted with analysis of variance followed by Newman-Keuls post hoc test. $\mathrm{P}<0.05$ was considered to indicate a statistically significant difference.

\section{Results}

circRNA-CER expression is increased in breast cancer tissues. To determine the expression levels of circRNA-CER, MMP13 and miR-136 in breast cancer tissues, circRNA-CER and miR-136 were quantified by RT-qPCR, whereas MMP13 was detected by IHC. The results revealed that the expression 
A
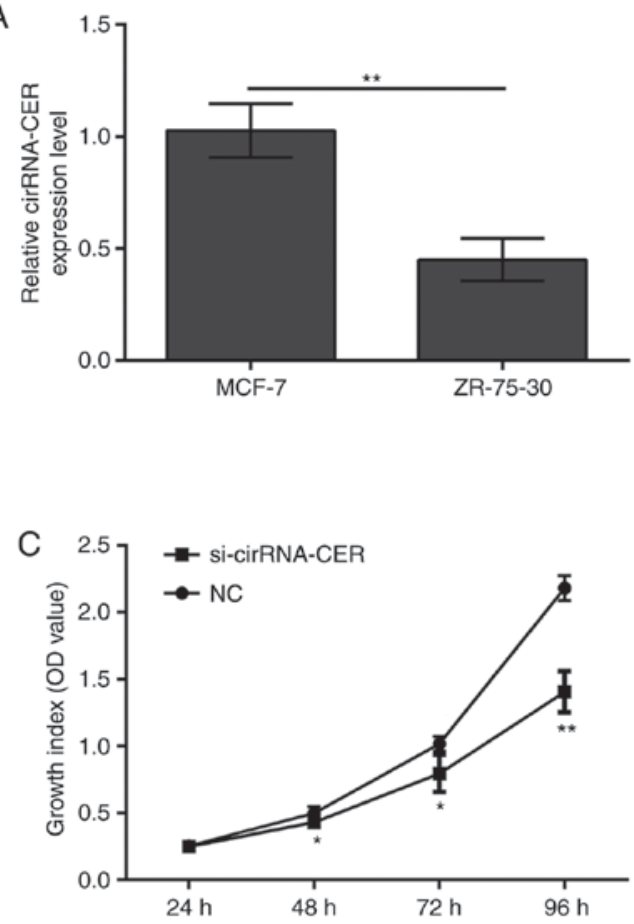

B
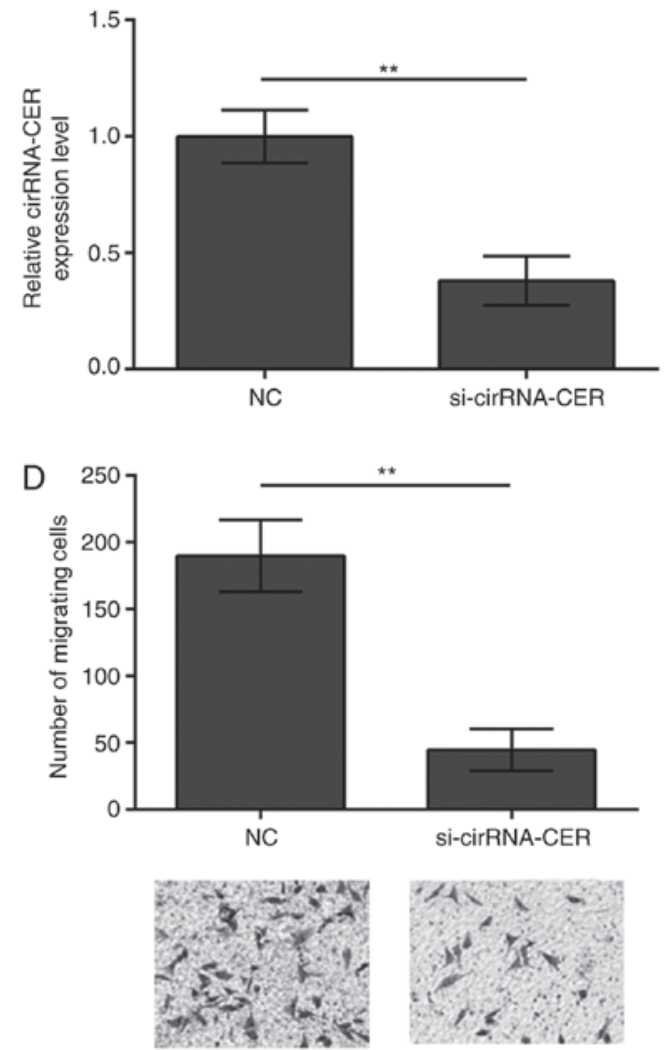

Figure 2. Knockdown of circRNA-CER suppresses proliferation and migration of MCF-7 breast cancer cells. (A) The expression levels of circRNA-CER in MCF-7 and ZR-75-30 breast cancer cells were evaluated by RT-qPCR. ${ }^{*} \mathrm{P}<0.01$. (B) MCF-7 cells were transfected with si-circRNA-CER and transfection efficiency was confirmed by RT-qPCR. ${ }^{* *} \mathrm{P}<0.01$. (C) Cell Counting Kit- 8 assays were performed. ${ }^{*} \mathrm{P}<0.05,{ }^{* * *} \mathrm{P}<0.01$ vs. NC. (D) Transwell migration assays (magnification, $\mathrm{x} 200$ ) were performed following MCF-7 cell transfection with si-circRNA-CER. ${ }^{* *} \mathrm{P}<0.01$. circRNA-CER, chondrocyte extracellular matrix-related circular RNA; NC, negative control; OD, optical density; RT-qPCR, reverse transcription-quantitative polymerase chain reaction; si, small interfering.

levels of circRNA-CER (Fig. 1A) and MMP13 (Fig. 1B) were significantly elevated in breast cancer tissues compared with in adjacent non-tumor tissues. Conversely, miR-136 expression was decreased in breast cancer tissues compared with in adjacent non-tumor tissues (Fig. 1C).

circRNA-CER knockdown inhibits MCF-7 cell proliferation and migration. To examine whether circRNA-CER mediates the malignant phenotype of breast cancer, its role in breast cancer cell proliferation and migration was investigated. RT-qPCR revealed that circRNA-CER expression was significantly higher in the MCF-7 cell line compared with in the ZR-75-30 cell line (Fig. 2A). Based on this observation, the MCF-7 cell line was selected for conducting silencing experiments, and the results demonstrated that silencing of circRNA-CER efficiently suppressed the expression of circRNA-CER (Fig. 2B). In addition, the results from the CCK-8 and Transwell assays indicated that knockdown of circRNA-CER significantly suppressed proliferation (Fig. 2C) and migration (Fig. 2D) of MCF-7 cells.

Overexpression of miR-136 inhibits $M C F-7$ cell proliferation and migration. The present study revealed that miR-136 expression levels were significantly lower in MCF-7 cells compared with in ZR-75-30 cells (Fig. 3A). Thus, miR-136 was overexpressed in MCF-7cells to evaluate the potential effects of miR-136 on breast cancer (Fig. 3B). The results demonstrated that overexpression of miR-136 in MCF-7 cells inhibited both cell proliferation (Fig. 3C) and migration (Fig. 3D).

circRNA-CER knockdown regulates the expression of miR-136 and its target gene MMP13. It is accepted that MMP13 is a target of miR-136 in human cartilage degradation (12). In accordance with this notion, the present study demonstrated that transfection with miR-136 mimics suppressed MMP13 protein expression in MCF-7 breast cancer cells (Fig. 4A). In addition, the results demonstrated that silencing of circRNA-CER increased the expression levels of miR-136 (Fig. 4B) and inhibited the protein expression of MMP13 (Fig. 4C), suggesting that miR-136/MMP13 crosstalk is regulated by circRNA-CER.

Knockdown of circRNA-CER suppresses MCF-7 cell proliferation and migration by targeting miR-136. To further demonstrate the association between circRNA-CER and miR-136, the present study conducted transfection experiments using miR-136 inhibitors to downregulate miR-136 expression in MCF-7 cells. The results revealed that miR-136 expression levels were successfully decreased; however, the presence of circRNA-CER knockdown reversed this effect (Fig. 5A). In addition, downregulation of miR-136 expression promoted MCF-7 cell proliferation and migration, and these biological effects were abolished upon silencing of circRNA-CER (Fig. 5B and C). 

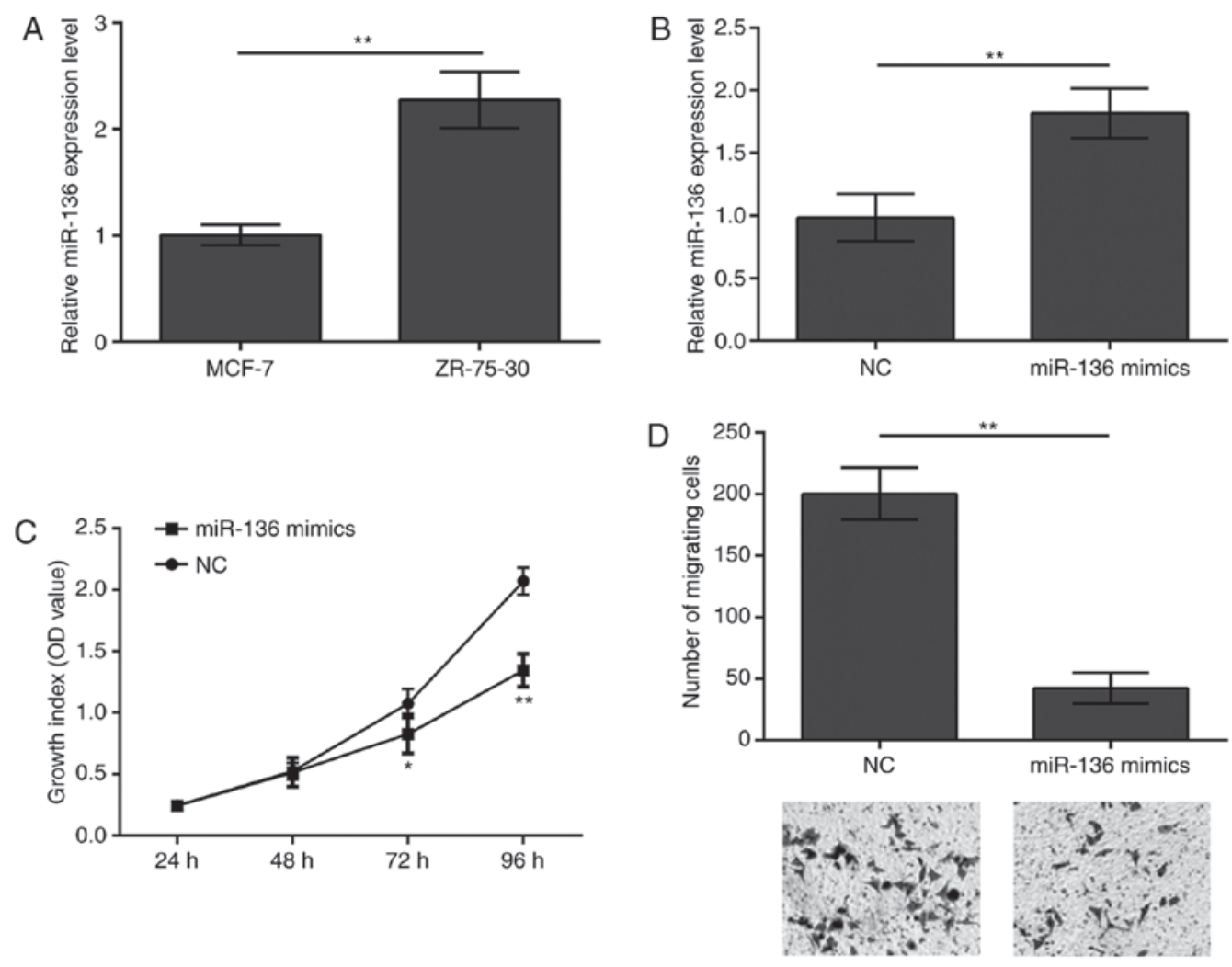

Figure 3. Overexpression of miR-136 inhibits MCF-7 cell proliferation and migration. (A) The expression levels of miR-136 in MCF-7 and ZR-75-30 breast cancer cells were evaluated by RT-qPCR. ${ }^{* *} \mathrm{P}<0.01$. (B) miR-136 overexpression in MCF-7 cells was confirmed by RT-qPCR. ${ }^{* *} \mathrm{P}<0.01$. (C) Cell Counting Kit- 8 assays were performed. "P $<0.05,{ }^{* * *} \mathrm{P}<0.01 \mathrm{vs.}$. NC. and (D) Transwell migration assays (magnification, $\mathrm{x} 200$ ) were performed using miR-136 mimics-transfected MCF-7 cells. ${ }^{* *} \mathrm{P}<0.01$. miR, microRNA; NC, negative control; OD, optical density; RT-qPCR, reverse transcription-quantitative polymerase chain reaction.

\section{Discussion}

Non-coding RNAs (ncRNAs), which include miRNAs, long ncRNAs and circRNAs, are involved in the development of several diseases including pathological cardiac remodeling, nervous system diseases and several cancers (16-19). circRNAs are a novel type of ncRNA characterized by a stable structure and highly specific tissue expression. circRNAs are more stable than linear RNAs due to their covalently closed continuous loop without a free $3^{\prime}$ or $5^{\prime}$ end and their polyadenylated tail (11). Several studies have proposed that circRNAs mediate diverse biological processes, including miRNA 'sponging', splicing and transcription regulation, protein binding and RNA transport (13).

The present study revealed that the levels of circRNA-CER were higher in breast cancer tissues compared with adjacent non-tumor tissues. Consistent with our findings, a previous study identified that among 101 patients with non-small cell lung cancer, the expression levels of circRNA-CER were significantly elevated in cancer tissues, which was markedly associated with lymph node metastasis, overall survival and tumor stage (13). To understand whether circRNA-CER is involved in the malignant progression of breast cancer, the present study conducted CCK-8 and Transwell assays. The results demonstrated that silencing of circRNA-CER inhibited the proliferation and migration of MCF-7 cells. In addition, silencing of circRNA-CER enhanced and decreased the expression levels of miR-136 and MMP13, respectively. Previously, Liu et al (12) demonstrated that circRNA-CER harbors binding sites form iRNAs, including miR-136, which can bind to the 3'-UTR of MMP13. Furthermore, downregulation of circRNA-CER by transfection with siRNA reduced MMP13 expression and increased extracellular matrix formation (12). These findings suggested that there exists crosstalk between circRNA-CER and the miR-136/MMP13 axis. To further confirm this, the present study performed proliferation and migration assays to assess the relationship between circRNA-CER and miR-136. The results revealed that silencing of miR-136 using miR-136 inhibitors resulted in an increase in MCF-7 cell proliferation and migration. The biological effects caused by miR-136 inhibitors were reversed by co-transfection with circRNA-CER siRNA, suggesting that circRNA-CER serves as a 'sponge' and competitively prevents miR-136 activity.

miRNAs have been demonstrated to serve a crucial role in regulation of human tumor initiation, development and metastasis (20). Several miRNAs are recognized to serve as potential tumor suppressors and their low expression levels are associated with upregulation of oncogenic genes in several types of cancer (21). An miRNA microarray expression assay identified that miR-136 is upregulated in human and murine lung cancers (22), and miR-136 was able to target the tumor suppressor phosphatase and tensin homolog (23), suggesting a potential role of miR-136 in the development of cancer. However, it is now well accepted that miR-136 may also function as a tumor suppressor, since it promotes the apoptosis of glioma cells by targeting astrocyte elevated gene-1 and B-cell lymphoma 2 (24). In breast cancer, miR-136 is considered as an anti-invasive miRNA due to its suppressive role in the mesenchymal migration and metastasis of breast cancer cells. Furthermore, its expression is downregulated in breast cancer tissues and 

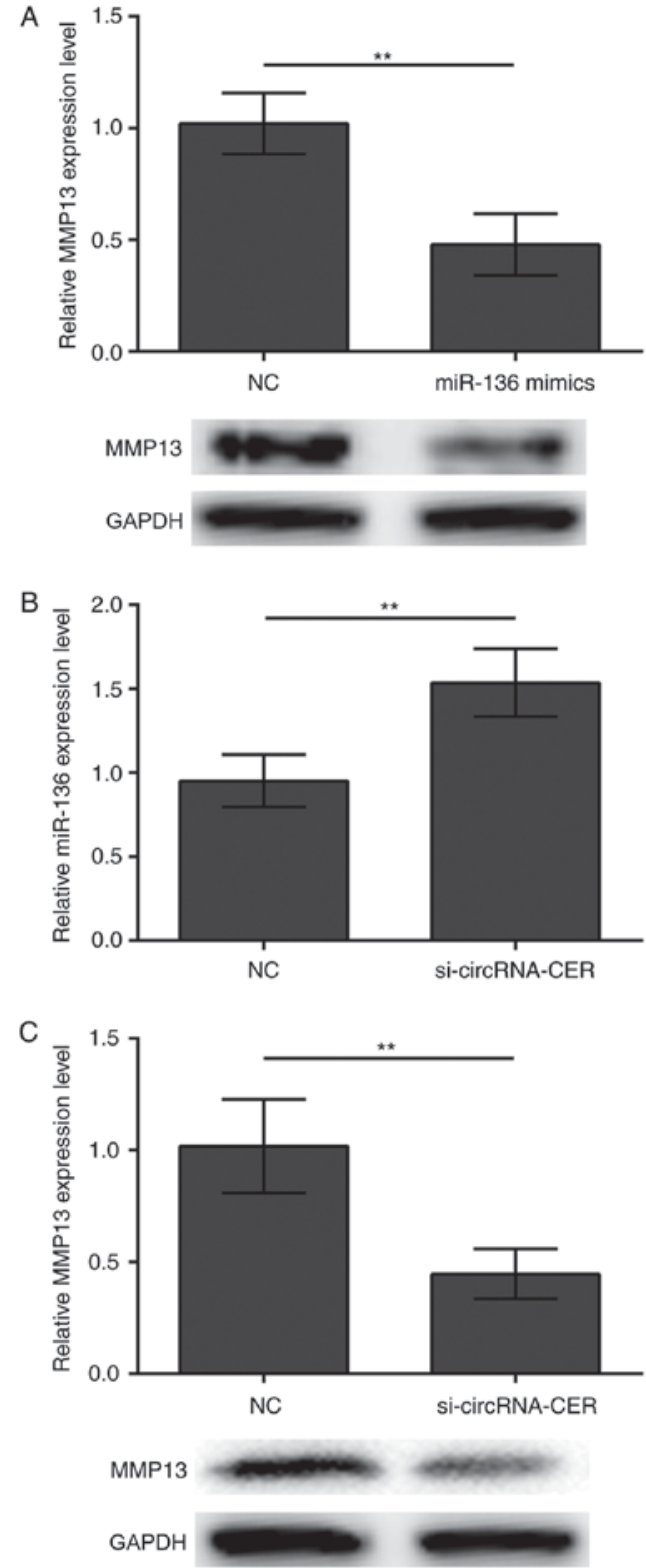

Figure 4. circRNA-CER regulates the miR-136/MMP13 axis. (A) MMP13 expression in miR-136 mimics-transfected MCF-7cells was examined by western blotting. (B) miR-136 and (C) MMP13 expression levels in MCF-7 cells transfected with si-circRNA-CER, were evaluated using reverse transcription-quantitative polymerase chain reaction and western blotting, respectively. ${ }^{* *} \mathrm{P}<0.01$. circRNA-CER, chondrocyte extracellular matrix-related circular RNA; MMP13, matrix metalloproteinase 13; miR, microRNA; NC, negative control; si, small interfering.

is negatively correlated with World Health Organization grades (25). In accordance with the above findings on miR-136 expression in breast cancer, the present study observed that miR-136 was downregulated, whereas its downstream molecule MMP13 was upregulated, in breast cancer tissues. MMP13 is a member of the human matrix metalloproteinase family, which comprises of 26 zinc-dependent transmembrane and secreted neutral endopeptidases that contribute to the homeostasis of the extracellular matrix (26). MMP13 is considered a potential new tumor marker for breast cancer diagnosis (27), and its elevated expression is closely associated with decreased overall survival and lymph node metastasis in breast cancer (28). By contrast, a selective inhibitor targeting MMP13 delays tumor growth
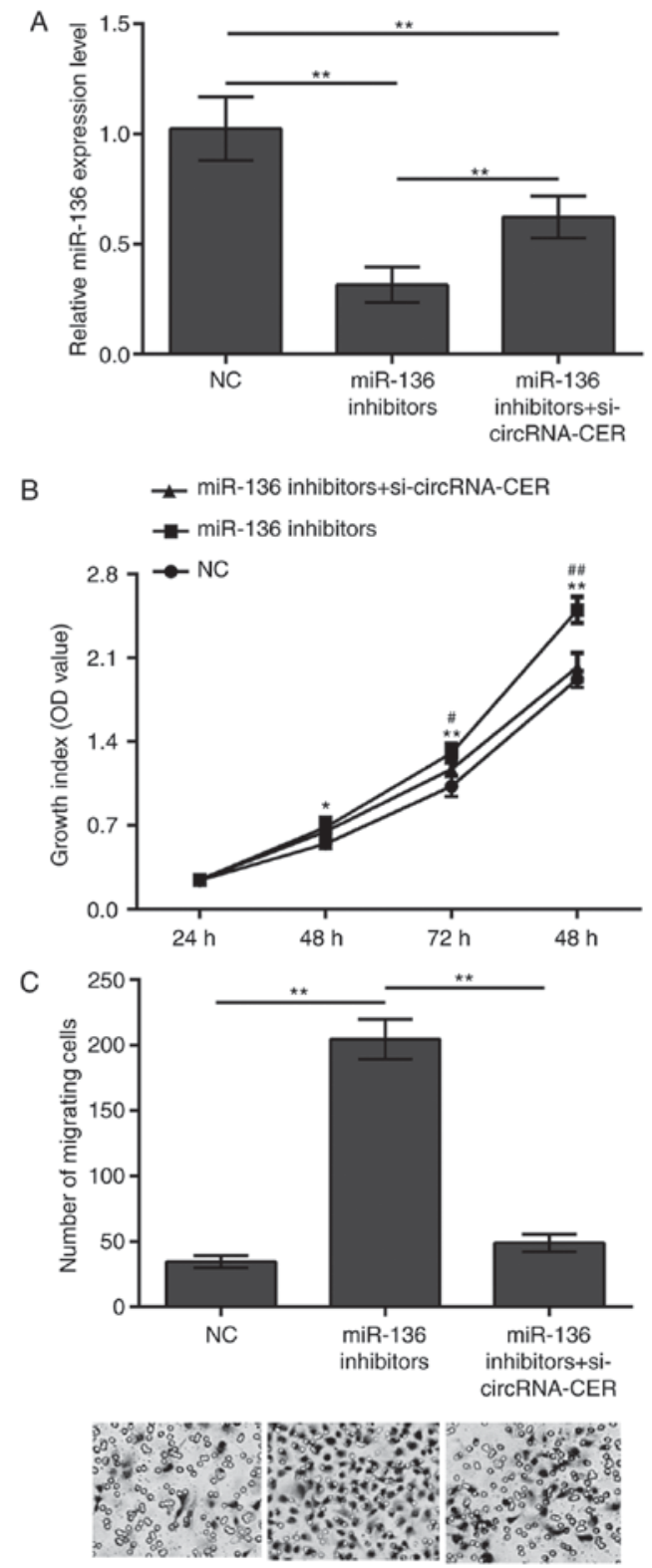

Figure 5. circRNA-CER knockdown suppresses MCF-7 cell proliferation and migration by targeting miR-136. (A) MCF-7 cells were transfected, with miR-136 inhibitors or miR-136 inhibitors + si-circRNA-CER, and miR-136 expression levels were determined by RT-qPCR. (B) CCK-8 and (C) Transwell migration assays (magnification, x200) were performed using MCF-7 cells transfected miR-136 inhibitors and miR-136 inhibitors + si-circRNA-CER. ${ }^{*} \mathrm{P}<0.05,{ }^{* *} \mathrm{P}<0.01$ vs. $\mathrm{NC} ;{ }^{\#} \mathrm{P}<0.05,{ }^{\#} \mathrm{P}<0.01$ vs. miR-136 inhibitors + si-circRNA-CER. ${ }^{* *} \mathrm{P}<0.01$. circRNA-CER, chondrocyte extracellular matrix-related circular RNA; miR, microRNA; MMP13, matrix metalloproteinase 13; NC, negative control; OD, optical density; si, small interfering.

and reduces the severity of tumor-associated osteolytic lesions in experimental models of breast cancer, indicating a potential therapeutic role for MMP13-selective inhibitors in primary breast cancer and cancer-induced bone osteolysis (29). In conclusion, the present study demonstrated that circRNA-CER expression was upregulated in breast cancer tissues compared with adjacent non-tumor tissues, and provided insight into the potential mechanisms of circRNA-CER in regulating the activity of the miR-136/MMP13 axis. The results supported the value of circRNA-CER as a possible molecular target for the diagnosis and treatment of breast cancer. 


\section{Acknowledgements}

Not applicable.

\section{Funding}

The present study was supported by the Research Project of the Education Department of Heilongjiang Province (grant no. 2016-KYYWF-0594).

\section{Availability of data and materials}

The datasets used and/or analyzed during the current study are available from the corresponding author on reasonable request.

\section{Authors' contributions}

HS designed the study and contributed to revision of the manuscript. YQ and PD performed cellular and molecular biology experiments and wrote the manuscript. MH participated in sample collection and immunohistochemistry experiments. JX performed cellular experiments. WX participated in the molecular biology experiments and data analysis. All authors read and approved the final manuscript.

\section{Ethics approval and consent to participate}

The present study was approved by the Ethics Committee of Jiamusi University (approval no. JMSU-215) and all patients provided written informed consent prior to enrolment.

\section{Patient consent for publication}

Not applicable.

\section{Competing interests}

The authors declare that they have no competing interest.

\section{References}

1. Zuo TT, Zheng RS, Zeng HM, Zhang SW and Chen WQ: Female breast cancer incidence and mortality in China, 2013. Thorac Cancer 8: 214-218, 2017.

2. Chen W, Zheng R, Baade PD, Zhang S, Zeng H, Bray F, Jemal A, Yu XQ and He J: Cancer statistics in China, 2015. CA Cancer J Clin 66: 115-132, 2016.

3. Zheng R, Zeng H, Zhang S, Chen T and Chen W: National estimates of cancer prevalence in China, 2011. Cancer Lett 370: 33-38, 2016.

4. Cancer Genome Atlas Network: Comprehensive molecular portraits of human breast tumours. Nature 490: 61-70, 2012.

5. Perou CM, Sørlie T, Eisen MB, van de Rijn M, Jeffrey SS, Rees CA, Pollack JR, Ross DT, Johnsen H, Akslen LA, et al: Molecular portraits of human breast tumours. Nature 406: 747-752, 2000.

6. Conn SJ, Pillman KA, Toubia J, Conn VM, Salmanidis M, Phillips CA, Roslan S, Schreiber AW, Gregory PA and Goodall GJ The RNA binding protein quaking regulates formation of circRNAs. Cell 160: 1125-1134, 2015.

7. Memczak S, Jens M, Elefsinioti A, Torti F, Krueger J, Rybak A Maier L, Mackowiak SD, Gregersen LH, Munschauer M, et al: Circular RNAs are a large class of animal RNAs with regulatory potency. Nature 495: 333-338, 2013.

8. Zhang Y, Zhang XO, Chen T, Xiang JF, Yin QF, Xing YH, Zhu S, Yang $L$ and Chen LL: Circular intronic long noncoding RNAs. Mol Cell 51: 792-806, 2013.
9. Jeck WR, Sorrentino JA, Wang K, Slevin MK, Burd CE, Liu J, Marzluff WF and Sharpless NE: Circular RNAs are abundant, conserved, and associated with ALU repeats. RNA 19: 141-157, 2013.

10. You X, Vlatkovic I, Babic A, Will T, Epstein I, Tushev G, Akbalik G, Wang M, Glock C, Quedenau C, et al: Neural circular RNAs are derived from synaptic genes and regulated by development and plasticity. Nat Neurosci 18: 603-610, 2015.

11. Guarnerio J, Bezzi M, Jeong JC, Paffenholz SV, Berry K, Naldini MM, Lo-Coco F, Tay Y, Beck AH and Pandolfi PP: Oncogenic Role of Fusion-circRNAs derived from cancerassociated chromosomal translocations. Cell 165: 289-302, 2016.

12. Liu Q, Zhang X, Hu X, Dai L, Fu X, Zhang J and Ao Y: Circular RNA related to the chondrocyte ECM regulates MMP13 expression by functioning as a miR-136 'Sponge' in human cartilage degradation. Sci Rep 6: 22572, 2016.

13. Yao JT, Zhao SH, Liu QP, Lv MQ, Zhou DX, Liao ZJ and Nan KJ: Over-expression of circRNA 100876 in non-small cell lung cancer and its prognostic value. Pathol Res Pract 213: 453-456, 2017.

14. Li RK, Zhao WY, Fang F, Zhuang C, Zhang XX, Yang XM, Jiang SH, Kong FZ, Tu L, Zhang WM, et al: Lysyl oxidase-like 4 (LOXL4) promotes proliferation and metastasis of gastric cancer via FAK/Src pathway. J Cancer Res Clin Oncol 141: 269-281, 2015.

15. Livak KJ and Schmittgen TD: Analysis of relative gene expression data using real-time quantitative PCR and the 2(-Delta Delta C(T)) method. Methods 25: 402-408, 2001.

16. Gao J, Xu W, Wang J, Wang K, and Li P: The role and molecular mechanism of Non-Coding RNAs in pathological cardiac remodeling. Int J Mol Sci 18: E608, 2017.

17. Soreq H: Novel roles of non-coding brain RNAs in health and disease. Front Mol Neurosci 7: 55, 2014.

18. Yang Y, Du Y, Liu X and Cho WC: Involvement of Non-coding RNAs in the signaling pathways of colorectal cancer. Adv Exp Med Biol 937: 19-51, 2016.

19. Hou LD and Zhang J: Circular RNAs: An emerging type of RNA in cancer. Int J Immunopathol Pharmacol 30: 1-6, 2017.

20. Farazi TA, Spitzer JI, Morozov P and Tuschl T: miRNAs in human cancer. J Pathol 223: 102-115, 2011.

21. Valastyan S, Reinhardt F, Benaich N, Calogrias D, Szász AM, Wang ZC, Brock JE, Richardson AL and Weinberg RA: A pleiotropically acting microRNA, miR-31, inhibits breast cancer metastasis. Cell 137: 1032-1046, 2009.

22. Liu X, Sempere LF, Ouyang H, Memoli VA, Andrew AS, Luo Y, Demidenko E, Korc M, Shi W, Preis M, et al: MicroRNA-31 functions as an oncogenic microRNA in mouse and human lung cancer cells by repressing specific tumor suppressors. J Clin Invest 120: 1298-1309, 2010.

23. Lee DY, Jeyapalan Z, Fang L, Yang J, Zhang Y, Yee AY, Li M, $\mathrm{Du} W W$, Shatseva T and Yang BB: Expression of versican 3'-untranslated region modulates endogenous microRNA functions. PLoS One 5: e13599, 2010.

24. Yang Y, Wu J, Guan H, Cai J, Fang L, Li J and Li M: miR-136 promotes apoptosis of glioma cells by targeting AEG-1 and Bcl-2. FEBS Lett 586: 3608-3612, 2012.

25. Yan M, Li X, Tong D, Han C, Zhao R, He Y and Jin X: miR-136 suppresses tumor invasion and metastasis by targeting RASAL2 in triple-negative breast cancer. Oncol Rep 36: 65-71, 2016.

26. Martin MD and Matrisian LM: The other side of MMPs: Protective roles in tumor progression. Cancer Metastasis Rev 26: 717-724, 2007.

27. Chang HJ, Yang MJ, Yang YH, Hou MF, Hsueh EJ and Lin SR: MMP13 is potentially a new tumor marker for breast cancer diagnosis. Oncol Rep 22: 1119-1127, 2009.

28. Zhang B, Cao X, Liu Y, Cao W, Zhang F, Zhang S, Li H, Ning L, Fu L, Niu Y, et al: Tumor-derived matrix metalloproteinase-13 (MMP-13) correlates with poor prognoses of invasive breast cancer. BMC Cancer 8: 83, 2008.

29. Shah M, Huang D, Blick T, Connor A, Reiter LA, Hardink JR, Lynch CC, Waltham M and Thompson EW. An MMP13-selective inhibitor delays primary tumor growth and the onset of tumor-associated osteolytic lesions in experimental models of breast cancer. PLoS One 7: e29615, 2012. 